\title{
PHYSICAL PROPERTIES OF CLAYS AND THEIR VARIATION
}

\author{
J. Kulenkampff, C. Flechsig, A. Just \\ Institute for Geophysics and Geology, Leipzig University (Germany)
}

\section{INTRODUCTION}

In geophysics, clays are known as materials which considerably influence and alter properties of 'clean' materials. Nevertheless, apart from results from more or less qualitative investigations of clay effects, not much is known about the geophysical properties of clays. Forming the barrier for fluid flow in the subsoil, and as a raw material, clays are of increasing economical and social interrest. This is the reason, why the Germany Research Foundation (DFG) granted projects in the area of petrophysical and geophysical investigations of clays. Clay properties are varying within a very large range, more than common materials - e.g. sands, limestones, crystalline rocks - with the variation depending on the condition (water content, consolidation, water salinity, contaminants) and composition of the clays. One main factor which controls the physical properties of clays is the small dimension of both the particles $(<2$ $\mu \mathrm{m})$ and the pore sizes. Therefore the internal surface area is very large $\left(10-1000 \mathrm{~m}^{2} / \mathrm{g}\right)$, and surface effects are prevailing.

These surface effects mainly comprise electrical effects: The internal surface of the minerals is usually negatively charged with about 1-3 elementary charges per $\mathrm{nm}^{2}$ (the order of $0.1 \mathrm{val} / \mathrm{kg}$ ), depending on electrochemical conditions. These surface charges cause the electrical double layer, with a high concentration of cathions near the mineral surface. The double layer thickness depends on the ion strength of the pore fluid and reaches $1-100 \mathrm{~nm} \rightarrow$ which is within the range of the prevalent pore radius. When the surface charge is caused by free valences at the mineral surface, then it depends on the $\mathrm{pH}$ of the fluid. It decreases or even changes the polarity with decreasing $\mathrm{pH}$. With increasing salinity of the fluid the surface effects decrease as well, because the double layer thickness and the surface electrical potential decrease. Therefore variations of the $\mathrm{pH}$ or the water salinity may cause the release of adsorbed elements, the reduction of repulsive forces between the clay particles, and the alteration of the clay structure. Similar effects are possible with some organic substances, when specific adsorption occurs. In summary, porosity, permeability, electrical and mechanical properties are varying with the fluid properties.

Within the scope of this project, we mainly study electrical and mechanical properties and their variation during some alterations of clays, which can be attained by simple means. 


\section{EXPERIMENTALS: INTEGRAL PROPERTIES}

For the first experiments and the development of the laboratory measuring methods we used a clay modelling paste, which mainly consists of caolinite (35\%), mica minerals $(10 \%)$, and $\mathrm{SiO}_{2}$ minerals $(40 \%)$. But various natural clays are also investigated.

We measured complex conductivity in the low frequency range $(10 \mathrm{mHz}-10 \mathrm{kHz})$ in a four electrode cell with Lock-In amplifiers for amplitude and phase measurements of current and voltage. A significant frequency dependence could not be observed, and the phase angle was found to be small (about $10 \mathrm{mrad}$, which is the resolution of the instruments). This is in contrast to results from consolidated sandstones with a clay content, which causes a rather strong frequency dependences and phase angles of more than $100 \mathrm{mrad}$.

Further electrical methods comprise complex conductivity measurements in the higher frequency range $(1 \mathrm{kHz}-1 \mathrm{MHz})$ and the dielectrical function in the frequency range from 1 $\mathrm{MHz}-1 \mathrm{GHz}$, as well as first NMR test measurements, which showed very short relaxation times.

Ultrasonic velocities were investigated in dependence from the water content, varying from clay suspensions with a water content about 70 vol. $-\%$ to oven dry conditions (at $50^{\circ} \mathrm{C}$ ) (Fig. 1). Starting at the water velocity (about $1500 \mathrm{~m} / \mathrm{s}$ ), it increases with decreasing water content to a maximum of nearly $2000 \mathrm{~m} / \mathrm{s}$ at a water content of $40 \mathrm{vol} .-\%$. At lower water content - after drying in the oven - the velocity decreases strongly downto $500 \mathrm{~m} / \mathrm{s}$, which is probably due to the increasing air content. Calculations of the ultrasonic absorption are not finished yet.

\section{EXPERIMENTALS: SPACE AND TIME DEPENDENCE}

In the past, electrical and acoustical tomography methods for the investigations of cores were developed in Leipzig (Just et al., 1997; Mayer et al., 1997; Just et al.,1995; Mayer et al., 1995). The electrical tomography setup consists of a computer controled positioning system for the four electrodes of the dipole-dipole arrangement around the core and two Lock-In amplifiers for current and voltage measurements, working at a frequency of $1.5 \mathrm{~Hz}$. The electrode positions are 15 degrees apart. The tomograms are calculated with a modified SIRT algorithm.

The ultrasonic tomography apparatus consists of a $500 \mathrm{kHz}$ transmitter and 32 equi-radially positioned receivers per transmitter point. The transmitter points are 5 degrees apart. They are coupled to the core in a water bath. Usually the arrival time of the pulse could be picked with a simple threshold criteria. These travel times were inverted to a tomogram with a SIRTalgorithm.

These measuring methods were adapted for measurements of unconsolidated clays: The clay was put into a cylindrical plastic container of the same size as the standard cores with 24 electrodes on the circumference for the resistivity mesurements. The ultrasonic cross section is positioned at $2 \mathrm{~cm}$ below the the electrical tomogram. The processing of the ultrasonic measurements thus were made difficult, because we had to take into consideration for the 
picking of the travel times that the travel time along the circumference of the plastic jacket is faster than in the clay, which made it necessary to pick most arrival times manually.

Nevertheless, we could monitore the evolution of cracks with electrical and acoustical tomography during the drying of the clay (Fig. 2, 1-4). The crack is visible at first sight because of its high resistivity and high acoustic traveltime, with quite low values of both resistivity and transit time in its vicinity.

A second experiment was the injection of concentrated salt brine into the center of the measuring plane (Fig. 2, 5-6). It strongly reduced the resistivity and obviously the salt concentration spreads out very quickly, within some hours.

In summary, geophysical methods can provide means for the investigation of clay properties and condition, because they are strongly varying. But a physically sound quantitative interpretation, based upon a realistic clay model, still requires more measurements under controled laboratory conditions with measurement procedures like ultrasonic and electrical tomography.

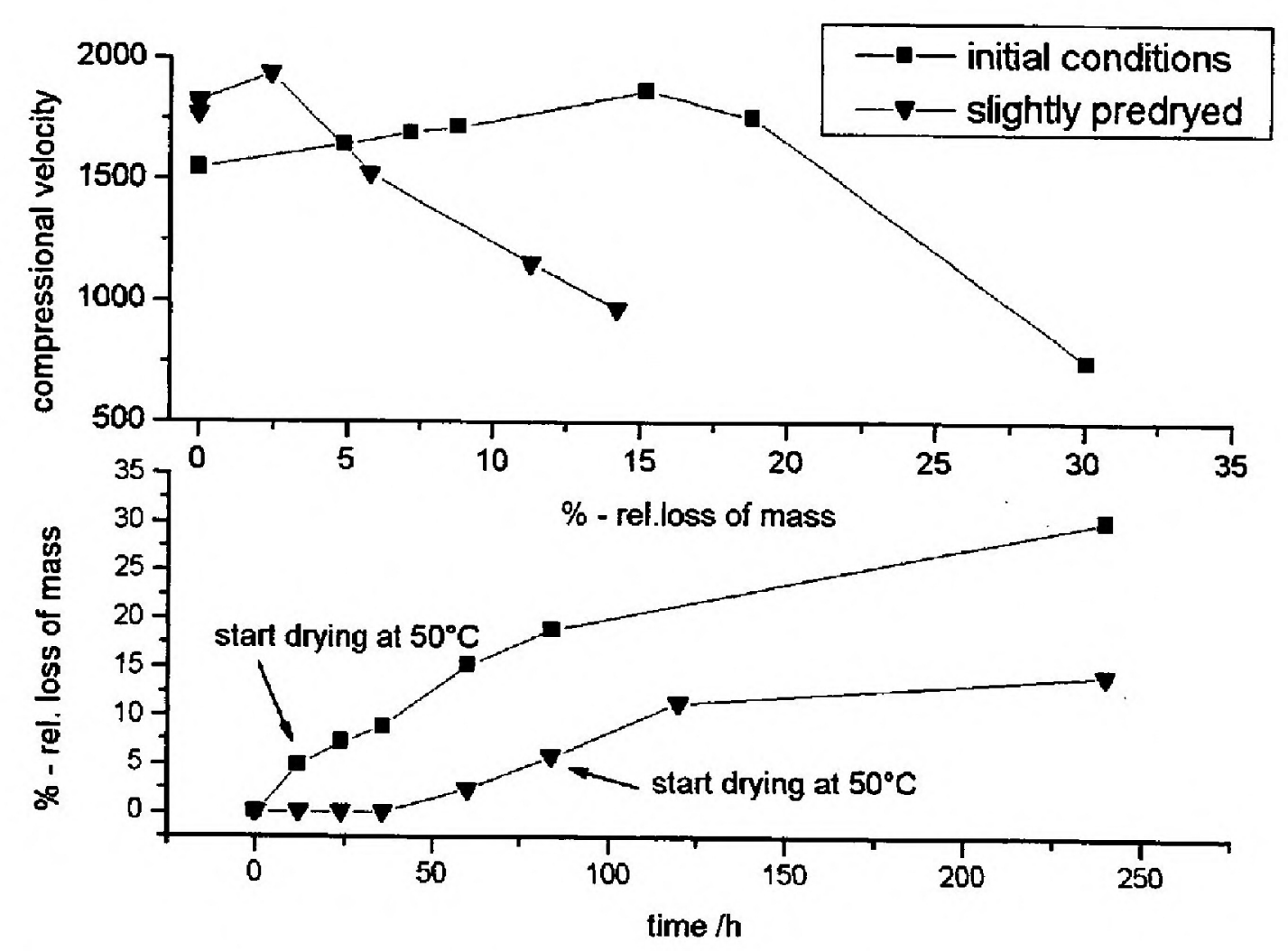

Fig. 1: Ultrasonic compressional velocity during drying of caolinite. 

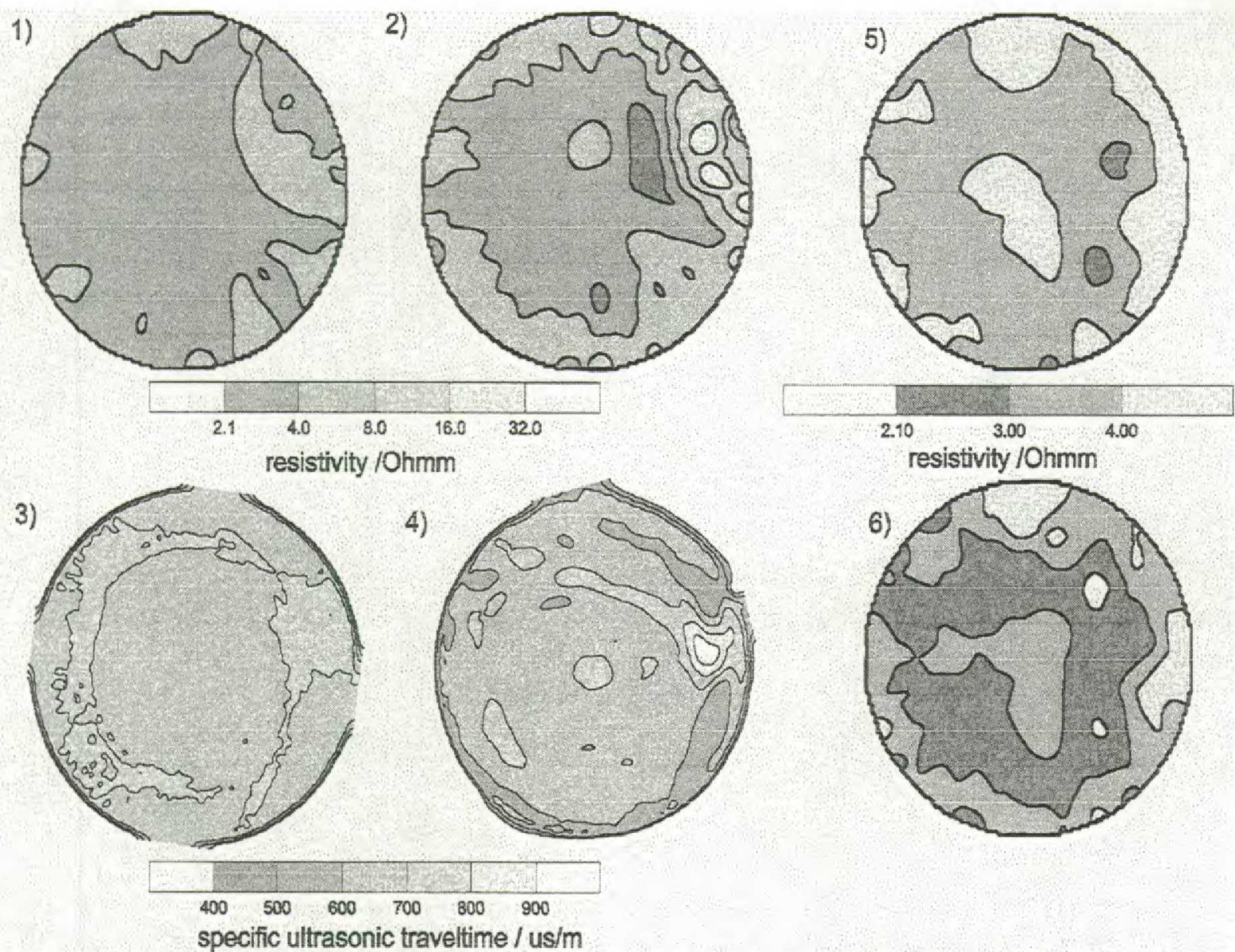

Fig. 2: Electrical and ultrasonic tomographies of clay samples ( $40 \%$ caolinite). The diameter of the samples is $9 \mathrm{~cm}$, the length is $20 \mathrm{~cm}$, and the measuring plane is at $10 \mathrm{~cm}$ below the surface.

1) initial resistivity tomogram,

2) resistivity tomogram after drying at atmosperical conditions over a period of 5 days.

3 ) initial ultrasonic tomogram (mesuring plane at $2 \mathrm{~cm}$ below the resistivity tomogram,

4) ultrasonic tomogram after a drying period of 4 days.

5) resistivity tomogram of a second sample,

6 ) resistivity tomogram of the sample from 5), 6 days after injection of concentrated $\mathrm{NaCl}-$ solution in the center of the measuring plane.

\section{REFERENCES}

Just, A., Küpper, T., Kürschner, D., Jacobs, F. (1995): Electrical Resistivity Tomography on Model Bodies and Drill Cores of the KTB. Contributions to the 8th annual KTB colloquium, Giessen.

Just, A., Küpper, T., Kürschner, D., Jacobs, F. (1997): Tomographie zur Bestimmung der räumlichen Leitfähigkeitsverteilung an Bohrkernen. - Leipziger Geowissenschaften, Leipzig (in press).

Mayer, P., Tietz, R., Flechsig, C., Jacobs, F. (1995): Anomaly Separation in Ultrasonic Tomography on KTB Drill Cores. Contributions to the 8th annual KTB colloquium, Giessen. Mayer, P., Tietz, R., Baumgart, M., Jacobs, F., Flechsig, C. (1997): Ergebnisse hochauflösender ultraschalltomographischer Untersuchungen an Bohrkernen. Z. geol. Wiss., 25 (1/2), Berlin. 